\title{
Long-term cost-effectiveness of the fixed-dose combination of tiotropium plus olodaterol based on the DYNAGITO trial results
}

This article was published in the following Dove Medical Press journal: International Journal of COPD

\author{
Martine Hoogendoorn' \\ Isaac Corro Ramos' \\ Michael Baldwin² \\ Laura Luciani ${ }^{3}$ \\ Cecile Fabron ${ }^{4}$ \\ Bruno Detournay ${ }^{4}$ \\ Maureen PMH Rutten-van \\ Mölken ${ }^{1,5}$ \\ 'institute for Medical Technology \\ Assessment (iMTA), Erasmus \\ University Rotterdam, Rotterdam, \\ the Netherlands; ${ }^{2}$ Boehringer \\ Ingelheim $\mathrm{GmbH}$, Ingelheim, Germany; \\ ${ }^{3}$ Boehringer Ingelheim France, Paris, \\ France; ${ }^{4}$ Cemka-Eval, Bourg-la-Reine, \\ France; ${ }^{5}$ Erasmus School of Health \\ Policy \& Management (ESHPM) \\ Erasmus University Rotterdam, \\ Rotterdam, the Netherlands
}

Purpose: Combinations of long-acting bronchodilators are recommended to reduce the rate of COPD exacerbations. Evidence from the DYNAGITO trial showed that the fixed-dose combination of tiotropium + olodaterol reduced the annual rate of total exacerbations $(P<0.05)$ compared with tiotropium monotherapy. This study aimed to estimate the cost-effectiveness of the fixed-dose combination of tiotropium + olodaterol vs tiotropium monotherapy in COPD patients in the French setting.

Patients and methods: A recently developed COPD patient-level simulation model was used to simulate the lifetime effects and costs for 15,000 patients receiving either tiotropium + olodaterol or tiotropium monotherapy by applying the reduction in annual exacerbation rate as observed in the DYNAGITO trial. The model was adapted to the French setting by including French unit costs for treatment medication, COPD maintenance treatment, COPD exacerbations (moderate or severe), and pneumonia. The main outcomes were the annual (severe) exacerbation rate, the number of quality-adjusted life-years (QALYs), and total lifetime costs.

Results: The number of QALYs for treatment with tiotropium + olodaterol was 0.042 higher compared with tiotropium monotherapy. Using a societal perspective, tiotropium + olodaterol resulted in a cost increase of $+€ 123$ and an incremental cost-effectiveness ratio (ICER) of $€ 2,900$ per QALY compared with tiotropium monotherapy. From a French National Sickness Fund perspective, total lifetime costs were reduced by $€ 272$ with tiotropium + olodaterol, resulting in tiotropium + olodaterol being the dominant treatment option, that is, more effects with less costs. Sensitivity analyses showed that reducing the cost of exacerbations by $34 \%$ increased the ICER to $€ 15,400$, which could still be considered cost-effective in the French setting.

Conclusion: Treatment with tiotropium + olodaterol resulted in a gain in QALYs and savings in costs compared with tiotropium monotherapy using a National Sickness Fund perspective in France. From the societal perspective, tiotropium + olodaterol was found to be cost-effective with a low cost per QALY.

Keywords: COPD, tiotropium, olodaterol, exacerbations, modeling, QALYs, costs

\section{Introduction}

Pharmaceutical treatment options for COPD focus on 1) reducing respiratory symptoms and the frequency and severity of exacerbations and 2) improving exercise tolerance and health status. ${ }^{1}$ The pharmacologic therapy for moderate-to-severe COPD usually includes long-acting bronchodilators, that is, long-acting $\beta 2$-agonists (LABAs) or long-acting muscarinic antagonists (LAMAs). A combination of two long-acting bronchodilators (LABA + LAMA) is recommended for patients with persistent or severe dyspnea, or with a high risk for exacerbations. Inhaled corticosteroids (ICS)
Correspondence: Martine Hoogendoorn institute for Medical Technology Assessment (iMTA), Erasmus University Rotterdam, Burgemeester Oudlaan 50, 3062 PA, Rotterdam, the Netherlands Tel +3 I I0 408 887।

Email hoogendoorn@imta.eur.nl 
and antibiotics can be used to treat and mitigate the effects of exacerbations. ${ }^{1,2}$ Overall, bronchodilation using a LAMA alone or in combination with a LABA is recommended for a large group of patients regardless of their COPD phenotype.

The fixed dose LABA/LAMA combination of once daily orally inhaled tiotropium + olodaterol $(5 / 5 \mu \mathrm{g})$ was found to have increased effectiveness with respect to lung function, physical functioning, and health-related quality of life compared with its mono-components. ${ }^{3-5}$ Recently, the impact of tiotropium + olodaterol on the annual rate of exacerbations was investigated in the DYNAGITO trial. This trial was a 52-week multi-national double-blind trial investigating the impact of once daily orally inhaled tiotropium + olodaterol $($ LAMA + LABA) $(5 / 5 \mu \mathrm{g})$ compared with tiotropium monotherapy $(5 \mu \mathrm{g})$ (LAMA) on the rate of exacerbations in patients with a history of exacerbations and $\mathrm{FEV}_{1} \%$ predicted below $60 \%{ }^{6}$ The trial showed that the annual rate of total exacerbations was reduced in the tiotropium + olodaterol arm, 0.90, compared with the tiotropium monotherapy arm, 0.97 (rate ratio [RR]: 0.93 [ $P$-value 0.0498]). The annual rate for severe exacerbations defined as a hospitalization was lower in the combination arm, 0.18 , compared with 0.20 for the tiotropium arm, but this difference was not statistically significant (RR: 0.89 [95\% CI: 0.76 to 1.03 ]).

Besides investigating the effectiveness of tiotropium + olodaterol compared with tiotropium monotherapy, it is also important to assess at what costs these additional effects are obtained. Given the continuously increasing health care expenditures, especially for medication, cost-effectiveness (CE) information becomes increasingly important to guide reimbursement decisions and clinical guideline development. Therefore, the aim of this study was to estimate the long-term $\mathrm{CE}$ of tiotropium + olodaterol vs tiotropium monotherapy in a French health care setting by applying the reduction in exacerbations observed in the DYNAGITO trial in a recently developed COPD CE model. ${ }^{7}$

\section{Materials and methods Model structure}

The patient-level discrete event simulation model used for the analysis has recently been developed and has been described in detail elsewhere. ${ }^{7}$ The model is unique because none of the previously developed health economic models for COPD included such a wide range of different patient characteristics and outcomes. Patient and disease characteristics included in the model are sex, age, body mass index (BMI), smoking status, number of pack-years, history of heart failure, other cardiovascular disease, asthma, diabetes and depression, bronchodilator responsiveness, presence of emphysema, eosinophil level, and use of ICS. These characteristics were assumed to influence the intermediate and final outcomes. Intermediate outcomes included in the model are exacerbations, pneumonia, lung function, exercise capacity, physical activity, symptoms, and disease-specific quality of life. Final outcomes are mortality, the number of qualityadjusted life-years (QALYs), and costs. The model consists of a series of consecutive regression equations describing the statistical associations between the aforementioned patient characteristics and changes in intermediate and final outcomes over time. These equations were estimated using the longitudinal, patient-level data of five large COPD trials evaluating tiotropium (UPLIFT, EXACTT, POET, TIOSPIR, and TONADO), ${ }^{3,8-11}$ Since only data from patients included in the tiotropium arms of the trials were used to estimate the regression equations, the outcomes of the equations are considered to reflect treatment with tiotropium. Starting point of the simulation is the baseline patient population of the same five large COPD trials evaluating tiotropium. ${ }^{3,8-11}$ The model then randomly samples one patient (with replacement). By filling in the patients' characteristics into the time-to-event regression equations, the time-to-exacerbation, pneumonia, and death are calculated. The event with the lowest predicted value (time) is assumed to happen first and intermediate outcomes, that is, lung function, exercise capacity, physical activity, symptoms, and disease-specific quality of life are updated at the time of the event by filling in the time passed and the (updated) patient and disease characteristics in the equations for outcomes. New times to events are then calculated using the updated values for the intermediate outcomes and the process is repeated again. Intermediate and final outcomes are updated every time an event occurs. The simulation continues until the patient dies, which occurs when the predicted event to happen first is death. Intermediate and final outcomes are also updated when a year has passed without event to avoid having few observations for patients with a low frequency of events. The process is repeated by randomly drawing multiple patients and simulating their individual disease progression over time until the moment of death. By combining the data of all simulated patients, the average change in intermediate and final outcomes is calculated. The standard time horizon of the model is lifetime and the model has been implemented in R using the software RStudio (version 1.1.383).

\section{Selected model population}

The model can be used to simulate results for a wide variety of subgroups by randomly sampling from the subgroup of 
interest in the total baseline patient population of the model. For the current analyses, we selected the subset of patients that met the DYNAGITO trial-specific inclusion criteria, that is, a post-bronchodilator $\mathrm{FEV}_{1} \%$ predicted to be $<60 \%$ and a history of at least one exacerbation in the 12 months before the trial. ${ }^{6}$ Other inclusion criteria of the DYNAGITO trial were also applied to sample a starting population that was similar to that in the trial.

\section{Treatment scenario}

Different intervention scenarios can be simulated with the model by applying different treatment effects. In the current study, we applied the rate ratios (RRs) as found in the DYNAGITO trial, of 0.93 and 0.89 for total and severe exacerbations, respectively. ${ }^{6}$ Because in the model, the risk of an exacerbation has been implemented as a time-to-event equation and not as an annual exacerbation risk, the time to exacerbation was calibrated by increasing it with a certain factor (about 8\% increase). This factor was chosen such that the RR of exacerbations in the tiotropium + olodaterol group compared with the tiotropium-only group was 0.93 . In addition, the outcome of the equation predicting the probability that an exacerbation is severe was adapted (about $4 \%$ reduction) in such a way that the model outcomes for severe exacerbations for the first year matched the RR of 0.89 observed in the DYNAGITO trial. The model was run for a life-time time horizon for 15,000 patients, assuming the DYNAGITO treatment effects are permanent and constant over time. In the comparator group reflecting treatment with tiotropium monotherapy, no changes were made to the model equations. According to the French guidelines for economic evaluation from HAS, costs and effects were discounted at $4 \%$ in the first 30 years and at $2 \%$ thereafter. ${ }^{12}$

\section{Perspective}

The CE study for the French setting was performed from two different perspectives. The National Sickness Fund perspective considered all health care-related costs that are reimbursed by the National Healthcare insurance and the cost of daily allowances paid to the patient when on sick leave. The societal perspective considered all health care costs that are reimbursed by both public and private insurance, patient co-payments for medication (non-reimbursed costs), and costs of productivity loss related to absence from paid work.

\section{Resource use and costs}

The model distinguishes between costs related to the use of study medication, for maintenance treatment, for exacerbations and for treatment of pneumonia. All health care use was valued in euros $(€)$ using unit costs from the year 2016 (Table 1). ${ }^{13-18}$ Costs related to study medication consisted of costs for either tiotropium + olodaterol or tiotropium monotherapy and were calculated as the number of days alive multiplied with the medication costs per day. ${ }^{13}$ Drug acquisition costs dispensed in retail pharmacies were taken from official list prices. Dispensing fees, reimbursement rates, and percentages of long-term illness have been considered for the medication costs per day.

Maintenance treatment included visits to primary and secondary care physicians, number of spirometries, use of influenza vaccinations, and use of ICS (Table 1). Based on two regression equations, the model predicts the annual number of visits to the general practitioner (GP) and the respiratory specialist using all baseline patient characteristics and intermediate outcomes as predictors. The outcome of the equations, that is, the predicted number of visits, was multiplied with a country-specific correction factor to make the resulting

Table I COPD-related health care use and unit costs for maintenance treatment for France

\begin{tabular}{|c|c|c|c|c|c|}
\hline Maintenance costs & $\begin{array}{l}\text { Country-specific } \\
\text { annual mean }\end{array}$ & $\begin{array}{l}\text { Non-country-specific } \\
\text { annual mean }\end{array}$ & $\begin{array}{l}\text { Unit costs } \\
\text { (National Sickness } \\
\text { Fund perspective) }\end{array}$ & $\begin{array}{l}\text { Unit costs } \\
\text { (societal } \\
\text { perspective) }\end{array}$ & References \\
\hline \multicolumn{6}{|l|}{ Treatment medication } \\
\hline Tiotropium + olodaterol & - & - & $€ 1.30$ per day & $€ 1.60$ per day & 13 \\
\hline Tiotropium & - & - & $€ 0.92$ per day & $€ I .0 I$ per day & 13 \\
\hline \multicolumn{6}{|l|}{ Visits + other medication } \\
\hline Primary care visits (GP) & 8.8 & Equation in the model & $€ 23.19$ per visit & $€ 26.07$ per visit & 14,15 \\
\hline Specialist visits & 1.1 & Equation in the model & $€ 52.05$ per visit & $€ 59.04$ per visit & 15,16 \\
\hline Spirometries & 1.4 & - & $€ 37.01$ per spirometry & $€ 41.57$ per spirometry & 16,17 \\
\hline Influenza vaccination (\%) & $50.4 \%$ & - & $€ 6.10$ per vaccination & $€ 6.10$ per vaccination & 13,18 \\
\hline ICS use & - & $\begin{array}{l}\text { Number of days alive } \\
\text { if ICS at baseline }\end{array}$ & $€ \mathrm{I} .17$ per day & $€ I .30$ per day & 13 \\
\hline
\end{tabular}

Abbreviations: -, not applicable; GP, general practitioner; ICS, inhaled corticosteroids. 
number of visits representative for the country of interest. This correction factor was calculated as the average number of COPD-related visits among COPD patients in a specific country divided by the average number of COPD-related visits among COPD patients predicted by the equation. In France, the mean annual number of COPD-related visits in patients with COPD was 8.8 for the GP and 1.1 for the respiratory specialist in patients with COPD. ${ }^{14,16}$ The doctor's fees have been calculated using open data from the National Health care Insurance database (DAMIR). ${ }^{15}$ The number of spirometries and the use of influenza vaccinations were assumed constant for all patients in the model and based on a study by Laurendeau et al and the guidelines from Jebrak. ${ }^{16,18}$ For all patients using ICS at baseline, cost of ICS was calculated by multiplying the number of days alive with the medication cost per day. ${ }^{13}$

Costs of exacerbations were specified separately for moderate and severe exacerbations. A moderate exacerbation was defined as an increase in respiratory symptoms requiring a visit to health care provider and treatment with antibiotics and/or oral steroids, whereas a severe exacerbation was defined as an increase in respiratory symptoms resulting in hospitalization. A study of Laurendeau et al $^{16}$ estimated the costs of moderate and severe exacerbation in France (Table 2), which were also used in previous cost analysis. ${ }^{19}$ Costs were specified for the National Sickness Fund and the societal perspectives below and above the age of 62 years, which is the mean retirement age in France. ${ }^{20}$ The mean number of working days lost in relation to a moderate and severe exacerbation for patients below the retirement age were based on the POET trial ${ }^{10}$ and were estimated to be 1.73 and 4.82 , respectively. These numbers were calculated while

Table 2 Exacerbation costs in France

\begin{tabular}{|l|l|l|}
\hline Total costs & $\begin{array}{l}\text { Moderate } \\
\text { exacerbation }\end{array}$ & $\begin{array}{l}\text { Severe } \\
\text { exacerbation }\end{array}$ \\
\hline $\begin{array}{l}\text { National Sickness Fund perspective } \\
\text { (below retirement age of 62 years) }\end{array}$ & $€ 80 \mathrm{I}$ & $€ 7,504^{\mathrm{a}}$ \\
\hline $\begin{array}{l}\text { National Sickness Fund perspective } \\
\text { (above retirement age of } 62 \text { years) }\end{array}$ & $€ 80 \mathrm{I}$ & $€ 7,438$ \\
\hline $\begin{array}{l}\text { Societal perspective } \\
\text { (below retirement age of } 62 \text { years) }\end{array}$ & $€ \mathrm{I}, 34 \mathrm{I}^{\mathrm{b}}$ & $€ 9,362^{\mathrm{c}}$ \\
\hline $\begin{array}{l}\text { Societal perspective } \\
\text { (above retirement age of } 62 \text { years) }\end{array}$ & $€ 866$ & $€ 8,037$ \\
\hline
\end{tabular}

Notes: Data from Laurendeau et al. ${ }^{16}$ a Costs from Laurendeau et al's study $+(4.81-3$ first days not paid=) I.8I $\times$ daily allowances of $€ 36.45$ per day. ${ }^{\text {bSocietal costs based }}$ on Laurendeau et al's study + productivity loss as observed in the POET trial (I.73 days lost for a moderate exacerbation) multiplied with the costs of one day lost, $€ 274.80$. 22,23 cSocietal costs based on Laurendeau et al's study + productivity loss as observed in the POET trial (4.82 days lost for severe exacerbation), multiplied with the costs of I day lost, $€ 274.80$. 22,23 taking into account that for a large part of the exacerbations, there was no productivity loss, because patients did not have a paid job anymore or the exacerbations had no impact on productivity. Costs related to productivity loss were calculated by multiplying the mean number of work days lost with the average wages per day in France. ${ }^{21-24}$ Costs of pneumonia with and without hospitalization were assumed to be the same as the costs for a moderate and severe exacerbation. This was done because the number of pneumonia in the model was very low and experts indicated that treatment for pneumonia did not differ much from the treatment for exacerbations.

\section{Health outcomes}

The model includes a wide variety of health outcomes: number of (severe) exacerbations, number of pneumonia, decline in lung function $\left(\mathrm{FEV}_{1}\right.$ in $\mathrm{mL}$ per year), exercise capacity (treadmill test in seconds), physical activity level (St George's Respiratory Questionnaire (SGRQ) sub-score for activity (range 0-100)), presence of symptoms (breathlessness and cough/sputum), disease-specific quality of life (SGRQ total score, range 0-100), remaining life-expectancy since start of the simulation (in years), and QALYs. For the current $\mathrm{CE}$ analysis, the main outcome of interest was the difference in QALYs between treatment with tiotropium + olodaterol and tiotropium monotherapy. The number of QALYs was calculated as the mean value of the utility value at start and end of a time period multiplied with the duration of the time period. Utility values at different time points were derived from the SGRQ total score using a previously published mapping algorithm. ${ }^{25}$

\section{Cost-effectiveness}

The incremental cost-effectiveness ratio (ICER) was calculated as the difference in the total average lifetime costs per patient between treatment with tiotropium + olodaterol and treatment with tiotropium monotherapy divided by the difference in the average number of QALYs per patient between the two treatments options.

\section{Sensitivity analyses (SA)}

Several one-way SA were performed on discount rate, time horizon, percentage of ICS users at baseline, and the cost estimates of exacerbations used in the analysis. For the first SA, results were calculated without discounting, while the second SA explored the impact of using a shorter time horizon, that is, 5 years. The percentage of patients using ICS was slightly different in the sampled patient population from the model (63\%) compared with the DYNAGITO 
trial (70\%). Consequently, a third SA was done using a patient population at the start of the model simulation with the same distribution of ICS users as observed in the trial, which was achieved by using weighted sampling. The study of Laurendeau et $\mathrm{a}^{16}$ reported estimates of exacerbation cost that included both COPD and non-COPD-related costs, while the original model only included COPD-related costs. For the fourth SA, 34\% lower estimates of the cost of a moderate and severe exacerbation were used to assess the impact of this difference. The factor of $34 \%$ was based on a study by Detournay et al presenting annual COPD-related costs and total costs among COPD patients showing that about $66 \%$ of the total costs were related to COPD. ${ }^{14}$ All SA were performed using the societal perspective.

In addition, probabilistic SA (PSA) were done for the main analysis. Besides patient heterogeneity due to the variation in sampled patients at start of the simulation, the PSA included two types of uncertainty: 1) stochastic uncertainty, which is uncertainty related to drawing random values from probability distributions during the simulation and 2) parameter uncertainty, which is uncertainty associated with the coefficients of the regression equations describing disease progression and the treatment effect parameters. The PSA was implemented as a double loop; an inner loop, in which a number of patients were sampled with replacement from the starting population of the model, and an outer loop in which values of the input parameters of the model were randomly drawn. For the current PSA, the model was run for 500 different sets of randomly drawn input parameters with a sample size of 100 patients per set, which was sufficient for the current analyses based on the paper of O'Hagan et al. ${ }^{26}$ For each set of randomly drawn coefficients, the mean outcomes over 100 patients were recorded, and the mean and 2.5th and 97.5th percentiles (uncertainty interval [UI]) over all 500 mean values for each outcome were calculated. The 500 resulting differences in QALYs and in costs between treatment with tiotropium + olodaterol vs tiotropium monotherapy were plotted in CE planes. A CE-plane is an $\mathrm{x}$-y diagram with the $\mathrm{x}$-axis representing the difference in QALYs between tiotropium + olodaterol vs tiotropium monotherapy and the y-axis representing the difference in costs. The information in the CE-plane is summarized in CE acceptability curves, which show the probability that treatment with tiotropium + olodaterol is cost-effective at several maximum willingness to pay values to gain one QALY.

\section{Results}

Table 3 shows the baseline characteristics of the sampled starting population for the model analysis and the patient
Table 3 Baseline characteristics of the 15,000 simulated patients of the model compared with the patients who participated in the DYNAGITO trial

\begin{tabular}{|l|l|l|}
\hline & $\begin{array}{l}\text { Model } \\
(15,000 \text { sampled } \\
\text { patients })\end{array}$ & $\begin{array}{l}\text { DYNAGITO } \\
\text { trial (tiotropium } \\
\text { arm })\end{array}$ \\
\hline Female, \% & 25.4 & 27.9 \\
\hline Age (years) & 64.0 & 66.3 \\
\hline FEV, (L) & 1.19 & 1.20 \\
\hline FEV,\% predicted & 42 & 44 \\
\hline Low BMI $\left(<21 \mathrm{~kg} / \mathrm{m}^{2}\right), \%$ & 18.1 & $18.3^{\mathrm{a}}$ \\
\hline Smokers, \% & 37.7 & 37.5 \\
\hline Pack-years & 42.8 & 44.7 \\
\hline ICS users, \% & 62.8 & 70.1 \\
\hline $\begin{array}{l}\text { Severe exacerbations in } \\
\text { previous year, \% }\end{array}$ & 28.7 & 27.4 \\
\hline SGRQ total score (points) & 47.5 & 47.4 \\
\hline
\end{tabular}

Note: aApproximated based on the mean BMI + SD.

Abbreviations: BMI, body mass index; ICS, inhaled corticosteroid; SGRQ, St George's Respiratory Questionnaire.

population in the tiotropium arm of the DYNAGITO trial. The patient populations were comparable with respect to the mean $\mathrm{FEV}_{1}$, percentage of people with a low BMI, smoking status, percentage of patients experiencing previous exacerbations, and mean value for disease-specific quality of life. Small differences were found in the percentage of female patients ( $25 \%$ vs $28 \%$ ), mean age (64 vs 66 years), and the number of pack-years (43 vs 45). The percentage of patients using ICS showed the greatest difference, $63 \%$ in the model vs $70 \%$ in the DYNAGITO trial. The impact of this difference on the outcomes was addressed in the SA.

For the first year of the simulation, the model predicted a total exacerbation rate of 0.805 per patient for treatment with tiotropium + olodaterol and 0.868 for treatment with tiotropium monotherapy, resulting in an RR of 0.93 . For severe exacerbations, the rates were 0.153 and 0.172 , respectively, resulting in an RR of 0.89 .

Table 4 shows the mean annual rates for total and severe exacerbations over lifetime. When comparing the two treatment options, the RRs over lifetime were 0.92 for the annual rate of total exacerbations and 0.87 for the annual rate of severe exacerbations. Comparison of the other clinical outcomes between the two treatment options showed that the remaining life-expectancy since start of the simulation was 0.1 year higher for treatment with tiotropium + olodaterol. Other clinical outcomes also improved but the improvements were very small (Table 4 ).

Compared with tiotropium monotherapy, treatment with tiotropium + olodaterol resulted in a QALY gain 
Table 4 Lifetime model results for treatment with tiotropium + olodaterol vs with tiotropium monotherapy

\begin{tabular}{|l|l|l|}
\hline & $\begin{array}{l}\text { Tiotropium }+ \\
\text { olodaterol }\end{array}$ & Tiotropium \\
\hline Severe exacerbation rate per year & 0.163 & 0.187 \\
\hline Total exacerbation rate per year & 0.724 & 0.786 \\
\hline Pneumonia per year & 0.039 & 0.040 \\
\hline Remaining life-expectancy since start of the simulation (years) & 9.94 & 9.84 \\
\hline Annual decline in lung function (mL) & -38.3 & -38.3 \\
\hline Annual change in exercise capacity (seconds) & -4.4 & -4.6 \\
\hline Annual change in physical activity (SGRQ activity score in points) & +1.52 & +1.53 \\
\hline Percentage of time periods with cough/sputum, \% & 66.1 & 66.2 \\
\hline Percentage of time periods with breathlessness, \% & 70.5 & 70.9 \\
\hline Annual change in disease-specific quality of life (SGRQ total score in points) & +1.04 \\
\hline Total number of QALYs (discounted) & +1.03 & 4.76 \\
\hline Total lifetime costs from the National Sickness Fund perspective (discounted) & 4.80 & $€ 22,433$ \\
\hline Total lifetime costs from the societal perspective (discounted) & $€ 22,16 \mathrm{I}$ & $€ 25,483$ \\
\hline
\end{tabular}

Abbreviations: QALYs, quality-adjusted life-years; SGRQ, St George's Respiratory Questionnaire.

of 0.042 (PSA: 0.043 [95\% UI: -0.015 to 0.102]). From the National Sickness Fund perspective, treatment costs were $€ 1,060$ higher for tiotropium + olodaterol. However, these higher costs were compensated by the reduction in exacerbation costs of $€ 1,355$. As a result, treatment with tiotropium + olodaterol resulted in $€ 272$ lower (PSA: $-€ 267$ [95\% UI: $-€ 1,318$ to $€ 533]$ ) total lifetime costs compared with tiotropium monotherapy. From a National Sickness Fund perspective, tiotropium + olodaterol was the dominant treatment option, that is, it showed a gain in QALYs and less costs. From the societal perspective, the higher treatment medication costs for tiotropium + olodaterol compared with tiotropium $(€ 1,643)$ were not completely offset by the reduction in exacerbation costs $(€ 1,540)$ (Figure 1).

As a result, total lifetime costs from the societal perspective were $€ 123$ higher (PSA: $€ 131$ [95\% UI: $-€ 1,021$ to $€ 1,026])$ for tiotropium + olodaterol compared with

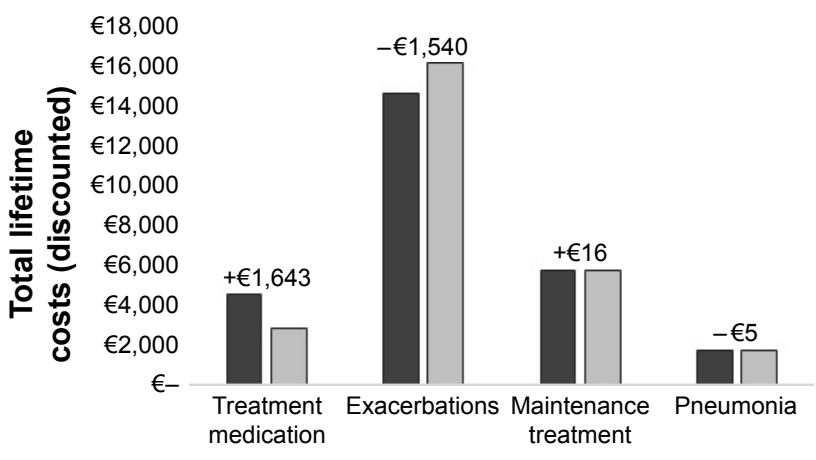

Figure I Lifetime costs per patient specified by category for treatment with tiotropium + olodaterol (black bars) vs tiotropium monotherapy (gray bars) (discounted costs from the societal perspective). tiotropium monotherapy resulting in an ICER of $€ 2,900$ per QALY gained. From the societal perspective, the CE-plane for the analysis (Figure 2) showed that in $93 \%$ of the PSA model simulations, tiotropium + olodaterol resulted in a gain in QALYs compared with tiotropium monotherapy, while in $35 \%$, it resulted in cost savings. From the National Sickness Fund perspective, these values were $93 \%$ and $73 \%$, respectively.

The acceptability curve for the societal perspective (Figure 3) showed that, the probability that treatment with tiotropium + olodaterol is cost-effective at different

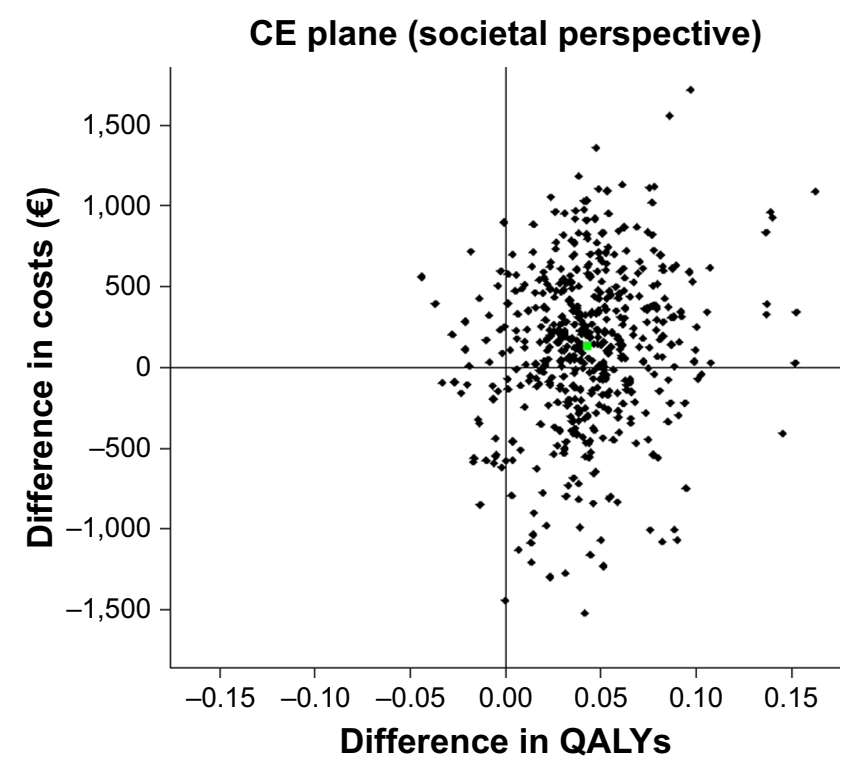

Figure $2 \mathrm{CE}$ plane for tiotropium + olodaterol vs tiotropium monotherapy based on discounted costs from the societal perspective.

Abbreviations: CE, cost-effectiveness; QALYs, quality-adjusted life-years. 


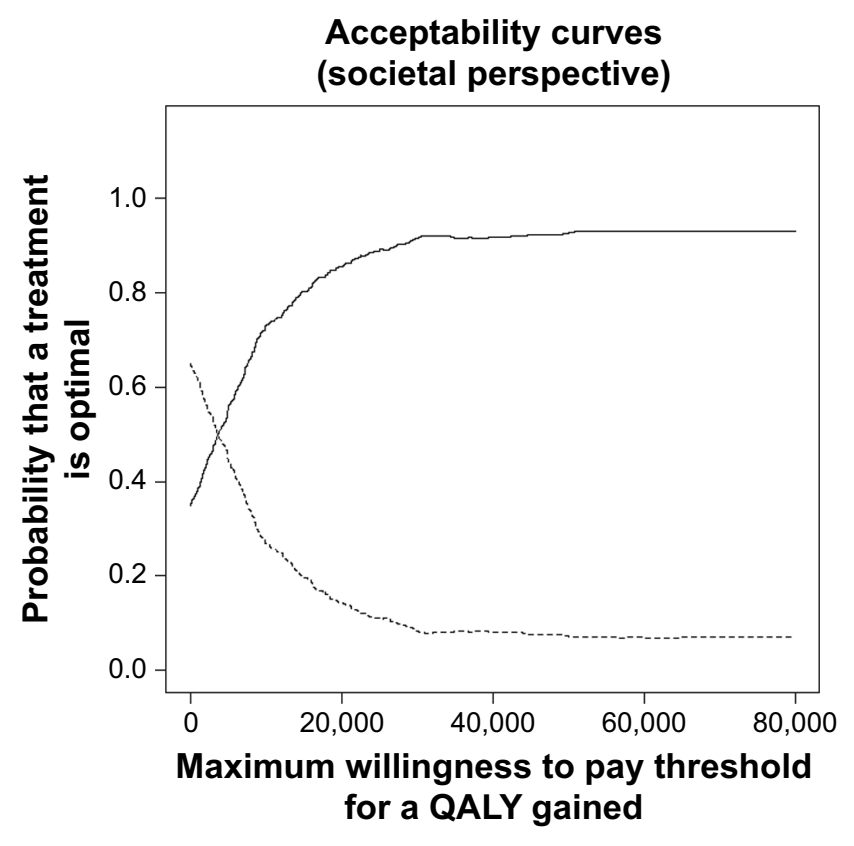

Figure 3 Cost-effectiveness acceptability curve for the costs per QALY gained for tiotropium + olodaterol (solid line) vs tiotropium monotherapy (dashed line) based on discounted costs from the societal perspective.

Abbreviation: QALYs, quality-adjusted life-years.

willingness to pay thresholds of $€ 10,000, € 20,000$, and $€ 40,000$ per QALY was $73 \%, 85 \%$, and $92 \%$, respectively. For the National Sickness Fund perspective, these values were $92 \%, 96 \%$, and $96 \%$, respectively.

Figure 4 shows the results of the SA using the societal perspective. All analyses resulted in a gain in QALYs and higher costs for tiotropium + olodaterol. No discounting and using a higher percentage of ICS users resulted in a reduction of the cost per QALY gained, while using a shorter time horizon and using 34\% lower cost estimates for exacerbations resulted in a slight increase of the ICER to $€ 15,400 / \mathrm{QALY}$, which could still be considered cost-effective in the French setting.

\section{Discussion}

The current study aimed to estimate the CE of the fixed dose combination of tiotropium + olodaterol vs tiotropium monotherapy in the French setting using the effectiveness results of the DYNAGITO trial, which demonstrated a lower rate of moderate-to-severe exacerbations compared with tiotropium monotherapy. The relative risk for exacerbations found in this trial was the main driver of the results. Exacerbation prevention is an important goal in the management of COPD and CE of interventions is highly dependent on the ability to prevent exacerbations, particularly, severe exacerbations that impact cost and health outcomes the most. In the current CE analysis, treatment with tiotropium + olodaterol was found to be cost-effective when compared with tiotropium monotherapy. From the societal perspective, treatment with tiotropium + olodaterol is associated with a low ICER of $€ 2,900$ per QALY gained vs tiotropium monotherapy. From a National Sickness Fund perspective, tiotropium + olodaterol is the dominant treatment, that is, more QALYs and less costs, compared with tiotropium monotherapy. In this analysis, the lifetime treatment medication cost was higher for tiotropium + olodaterol, but this was completely compensated by a reduction in cost for COPD exacerbations. From the societal perspective, the higher treatment medication costs were not completely compensated by the reduction in exacerbation costs, but the cost difference was small at $+€ 123$. The difference between the results from the National Sickness Fund and the societal perspectives can be explained by a smaller difference in medication cost between tiotropium + olodaterol and

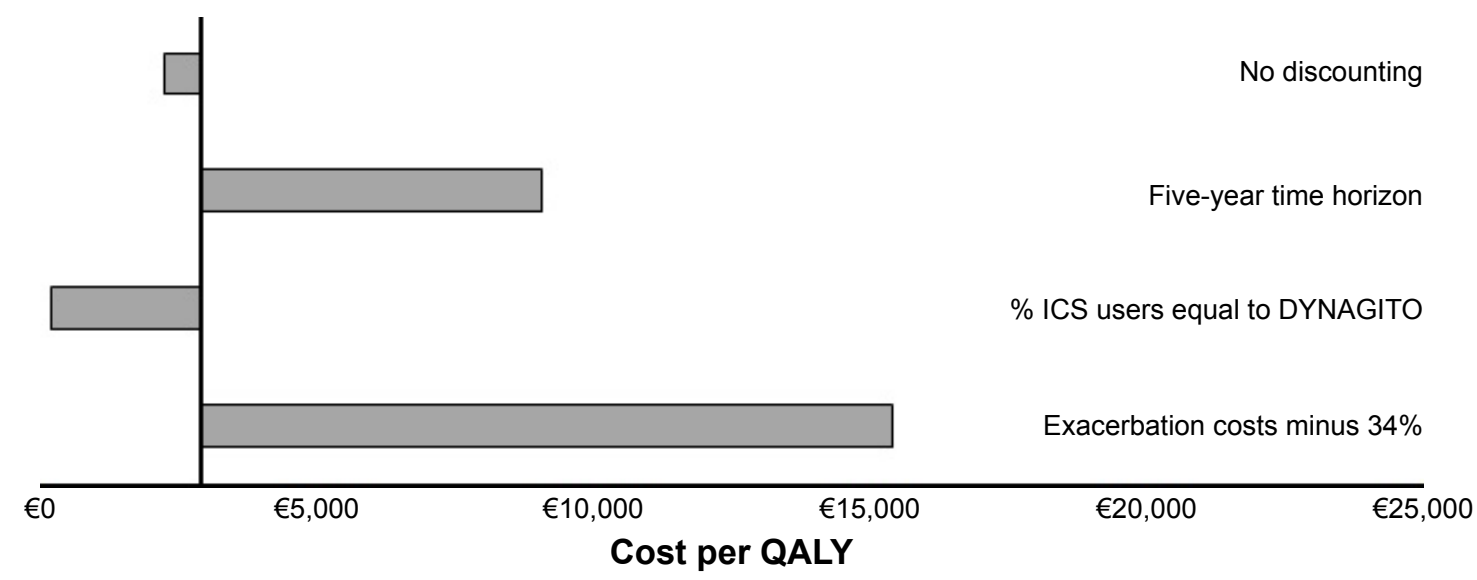

Figure 4 Sensitivity analysis on cost per QALY gained for tiotropium + olodaterol vs tiotropium monotherapy based on discounted cost from the societal perspective (reference ICER of the main analysis: €2,900/QALY gained).

Abbreviations: ICER, incremental cost-effectiveness ratio; ICS, inhaled corticosteroids; QALYs, quality-adjusted life-years. 
tiotropium monotherapy from the National Sickness Fund perspective $(+€ 0.38$ per day) compared with the societal perspective (+€0.59 per day) because the latter includes the additional costs of medication not covered by the National Sickness Fund (Table 2). Results were robust to changes in several assumptions with all performed SA resulting in ICERs below $€ 20,000$ per QALY gained.

Two previous studies investigated the CE of the fixeddose combination of olodaterol + tiotropium vs tiotropium monotherapy. Selya-Hammer et al reported a $\mathrm{CE}$ ratio of $€ 7,518$ per QALY gained for treatment with olodaterol + tiotropium using a time horizon of 15 years and the perspective of the Italian National Health Service. ${ }^{27}$ van Boven et al performed a CE analysis from the Dutch health care payer's perspective using a 15 -year time horizon and found a $\mathrm{CE}$ ratio of $€ 7,004$ per QALY gained. ${ }^{28}$ In both studies, the difference in effectiveness of olodaterol + tiotropium vs tiotropium monotherapy was modeled as an increase in trough $\mathrm{FEV}_{1}$ in the first 52 weeks based on the results of the TONADO trial, ${ }^{3}$ but no direct reduction in exacerbations was modeled. As a result of the improved lung function, a slight indirect reduction in annual exacerbation rate was observed in both studies as well as a small improvement in life-expectancy. In the current study, a direct effect on exacerbations was modeled, but no direct improvement in lung function was included, although the current model includes a small indirect effect of reducing the number of moderate and severe exacerbations on lung function. Therefore, the $\mathrm{CE}$ ratios found in the current study are most likely conservative estimates as are the estimates in the previous studies. ${ }^{27,28}$

In the DYNAGITO trial, a large part of the patients was using ICS (70\%). Post hoc analysis of the DYNAGITO trial showed that tiotropium + olodaterol was more effective compared with tiotropium monotherapy in the subgroup of patients using ICS at baseline, but not in non-ICS users. ${ }^{6}$ For the current study, we did not perform any subgroup analysis. The treatment effect of tiotropium + olodaterol vs tiotropium monotherapy, the exacerbation RR, in the model was based on the combined patient population of ICS and non-ICS users. The model outcomes are, therefore, representative of a population with about two-third of ICS users. This means that results in terms of CE found in the current study cannot be extrapolated to the group of COPD patients not using ICS. It should also be noted that the RR used to model the difference in treatment effect between tiotropium + olodaterol and tiotropium monotherapy was assumed constant over the total remaining lifetime of the patient. One of the SA showed that using a 5-year time horizon instead of a lifetime horizon still resulted in a cost per QALY gained below $€ 10,000 / \mathrm{Q} A L Y$, so treatment with tiotropium + olodaterol can also be considered cost-effective in the short run. Discontinuation of treatment was also not taken into account, which was in line with the exacerbation RRs presented in the DYNAGITO trial that were based on exacerbation rates during actual treatment.

The strength of the current study is that the model used for the CE analysis is a very comprehensive model, including a wide range of outcomes. Thus, besides showing the final results in terms of QALYs and costs, the model is also capable of showing the impact of reduction in exacerbations on annual lung function decline, exercise capacity, physical activity, symptoms, disease-specific quality of life, and remaining life-expectancy (as shown in Table 4). Another strength of the model is that it has been built using the combined data from five large tiotropium trials, including data from a total number of about 35,000 patients.

A limitation of the current study is that QALYs in the model are not based on utility values that are directly measured, but based on utility values that are derived from SGRQ total scores using a previously published algorithm for the UK. ${ }^{25}$ Using a so-called mapping algorithm has disadvantages, because it seems to underestimate utility values in milder health states and overestimate values in more severe health states and utilities cannot be translated to other countries. ${ }^{29}$ This might have influenced the QALY calculations. However, because the large tiotropium trials used to build the model did not include sufficient data on utility values, equation-predicted utility values based on different patient and disease characteristics could not be estimated. Hence, using a mapping algorithm was the only possible solution to derive utilities. Regarding costs, the model includes COPD-related costs for a substantial number of healthcare services: treatment medication, GP and specialist visits, spirometries, influenza vaccinations, concomitant medication, costs for exacerbations, and costs of pneumonia. However, some important costs were not included in the model, such as costs of visits to respiratory nurses, costs of pulmonary rehabilitation, or cost related to long-term oxygen use. Because this results in an underestimation of total costs for both tiotropium + olodaterol and tiotropium monotherapy, the impact on the cost difference between the two treatment options was expected to be small. For the current study, the model was adapted to the French setting by including unit costs in France for all different types of medication and health care use. The only data source available to provide cost estimates for the cost of a moderate and severe exacerbation in France was the study by Laurendeau et al. ${ }^{16}$ The estimates reported in this study were used in other studies as well, ${ }^{19}$ and are based on the 
French medico-administrative databases (French general beneficiary sample database EGB). The main disadvantage of using these estimates was that the estimates included both COPD- as well as non-COPD-related costs, while the model only included COPD-related costs. To test the impact of using the higher cost estimates for exacerbations, an SA was done with 34\% lower cost estimates, which showed that the ICER remained in the range considered cost-effective in France.

The model used for the analyses was extensively validated. ${ }^{7}$ For the current study, the exacerbation rates for tiotropium monotherapy predicted by the model in the first year were compared with the rates as reported for the tiotropium arm of the 1-year DYNAGITO trial. ${ }^{6}$ This validation exercise showed that the exacerbation rates predicted by the model for the first year were comparable with the observed exacerbations rates in the DYNAGITO trial, 0.87 vs 0.88 for total exacerbations and 0.17 vs 0.17 for severe exacerbations. For the DYNAGITO trial, the adjusted exacerbation rates for the tiotropium arm based on the negative binomial regression model were higher, namely, 0.97 for total exacerbations and 0.20 for severe exacerbations. ${ }^{6}$ The 1 -year mortality rate predicted by the model was higher than that observed in the DYNAGITO trial, $4.6 \%$ vs $3.1 \%$, which seems to indicate that the model is overestimating mortality somewhat. ${ }^{6}$ Because this was done for both tiotropium + olodaterol and tiotropium monotherapy, the impact on the differences between the treatment options is limited.

The model outcomes were representative for the group of patients that participated in the large tiotropium trials, that is, secondary care patients with moderateto-severe airflow obstruction and no life-treating other diseases. This is relevant because the effectiveness data for olodaterol + tiotropium were also based on trial data, that is, the DYNAGITO trial. However, it does limit the extrapolation of the results to the total COPD population, because a large proportion of COPD patients has mild-tomoderate airflow limitation, is treated in primary care, and has a substantial number of comorbidities. ${ }^{30}$

\section{Conclusion}

This model-based analysis showed that on the basis of the results of a large and robust exacerbation trial, the fixed-dose combination of tiotropium + olodaterol is the dominant treatment option, that is, providing more QALYs for less costs, compared with tiotropium monotherapy from the French National Sickness Fund perspective. From the societal perspective, tiotropium + olodaterol can be considered a cost-effective therapeutic option compared with tiotropium monotherapy. This finding was consistent across all SA that were conducted.

\section{Acknowledgments}

This study was financially supported by Boehringer Ingelheim GmbH. The study sponsor had no role in the study design, data analysis, data interpretation, writing of the manuscript, or the decision to submit the manuscript. Results of this study were presented as a poster presentation at the European Respiratory Society International Congress, 2018, and the poster's abstract has been published. ${ }^{31}$ Results have also been presented as a poster presentation at the annual European Congress of the International Society for Pharmacoeconomics and Outcomes Research (ISPOR), 2018, and the poster's abstract has been published. ${ }^{32}$

\section{Disclosure}

$\mathrm{MB}$ is employed by Boehringer Ingelheim $\mathrm{GmbH}$, Ingelheim, Germany. LL is employed by Boehringer Ingelheim France, Paris, France. CF and BD are employed by Cemka-Eval, Bourg-la-Reine, France. The authors report no other conflicts of interest in this work.

\section{References}

1. Global strategy for the diagnosis, management and prevention of COPD. Global Initiative for Chronic Obstructive Lung Disease (GOLD) Report. 2017. Available from. http://goldcopd.org/gold-2017-global-strategydiagnosis-management-prevention-copd/. Accessed March 9, 2018.

2. HAS. Guide Du parcours de soins. Jun 2014 [French National Authority for Health (HAS). Health care Management in COPD. June 2014]. Available from: https://www.has-sante.fr/portail/upload/docs/application/pdf/2012-04/guide_parcours_de_soins_bpco_finale.pdf. Accessed November 2016. French.

3. Buhl R, Maltais F, Abrahams R, et al. Tiotropium and olodaterol fixeddose combination versus mono-components in COPD (Gold 2-4). Eur Respir J. 2015;45(4):969-979.

4. Sauer R, Hänsel M, Buhl R, Rubin RA, Frey M, Glaab T. Impact of tiotropium + olodaterol on physical functioning in COPD: results of an open-label observational study. Int J Chron Obstruct Pulmon Dis. 2016; 11:891-898.

5. Singh D, Ferguson GT, Bolitschek J, et al. Tiotropium + olodaterol shows clinically meaningful improvements in quality of life. Respir Med. 2015;109(10):1312-1319.

6. Calverley PMA, Anzueto AR, Carter K, et al. Tiotropium and olodaterol in the prevention of chronic obstructive pulmonary disease exacerbations (DYNAGITO): a double-blind, randomised, parallel-group, active-controlled trial. Lancet Respir Med. 2018;6(5):337-344.

7. Hoogendoorn M, Corro Ramos I, Baldwin M, Gonzalez-Rojas Guix N, Rutten-van Mölken MPMH. Broadening the perspective of cost-effectiveness modeling in chronic obstructive pulmonary disease: a new patient-level simulation model suitable to evaluate stratified medicine. Value in Health. In press 2019.

8. Tashkin DP, Celli B, Senn S, et al. A 4-year trial of tiotropium in chronic obstructive pulmonary disease. NEngl J Med.2008;359(15):1543-1554.

9. Cooper CB, Celli BR, Jardim JR, et al. Treadmill endurance during 2-year treatment with tiotropium in patients with COPD: a randomized trial. Chest. 2013;144(2):490-497.

10. Vogelmeier C, Hederer B, Glaab T, et al. Tiotropium versus salmeterol for the prevention of exacerbations of COPD. $N$ Engl J Med. 2011; 364(12):1093-1103. 
11. Wise RA, Anzueto A, Cotton D, et al. Tiotropium Respimat inhaler and the risk of death in COPD. N Engl J Med. 2013;369(16):1491-1501.

12. Choices in methods for economic evaluation, a methodological guide (report). 2012. Haute Authorité de Santé, Saint-Denis La Plaine, France. Available from: https://www.has-sante.fr/portail/upload/docs/application/pdf/2012-10/choices_in_methods_for_economic_evaluation.pdf. Accessed November 2017.

13. Base de données publique des medicaments. 2017. Ministère des Solidarités et de la Santé [Public drug database. Ministry of Solidarity and Health]. Available from: http://base-donnees-publique.medicaments. gouv.fr/index.php\#result. Accessed November 2017. French.

14. Detournay B, Pribil C, Fournier M, et al; Scope Group. The scope study: health-care consumption related to patients with chronic obstructive pulmonary disease in France. Value Health. 2004;7(2):168-174.

15. Dépenses d'Assurance Maladie Inter Régime (DAMIR) from the French Sickness Fund 2016 [Inter-Plan Health Insurance Expenses (DAMIR) from the French Sickness fund 2016]; [database - not publicly available]. French.

16. Laurendeau C, Chouaid C, Roche N, Terrioux P, Gourmelen J, Detournay B. Prise en charge et coûts de la bronchopneumopathie chronique obstructive en France en 2011 [Management and costs of chronic pulmonary obstructive disease in France in 2011]. Revue des Maladies Respiratoires. 2015;32(7):682-691. French.

17. Classification commune des Actes Médicaux [Common Classification of Medical Acts]. Available from: https://www.ameli.fr/accueil-de-laccam/index.php. Accessed November 2017. French.

18. Jebrak G, Initiatives BPCO. [COPD routine management in France: are guidelines used in clinical practice?]. Rev Mal Respir. 2010;27(1): $11-18$.

19. CNAMTS (french national health fund). Etude des algorithmes de definition de pathologies dans le système Nationale d'information inter-regimes de l'assurance maladie (SNIIRAM) Caisse Nationale d'Assurance Maladie des travailleurs Salariés [CNAMTS (French national health fund). Study of algorithms to define pathologies in the SNIIRAM from the French national health fund]; 2015. Available from: https://www.ameli.fr/fileadmin/user_upload/documents/ Rapport_Etude_algorithmes_partie1.pdf. Accessed January 2018. French.

20. OECD. Average effective age of retirement versus the normal retirement age; 2011-2016. Available from: http://www.oecd.org/els/emp/ average-effective-age-of-retirement.htm. Accessed November 2017.
21. Debauche E, Arnaud F, Gallot P. ES comptes de la nation en 2015, Insee Première $\mathrm{n}^{\circ}$ 1597. Mai. 2016 [Account of the nation in 2015 Insee number 1597. May 2016]. French.

22. Beck S, Vidalenc J. Une photographie du marché du travail en 2015, Insee Première $n^{\circ}$ 1602. Juin. 2016 [A picture of the job market in 2015. Insse number 1602]. French.

23. Létroublon C, Zilloniz S, Travail. la Durée du. principaux indicateurs, Dares résultatsn ${ }^{\circ} 080$. Décembre. 2016 [Duration of the main indicators. DARES Results number 808. December, 2016]. French.

24. Communiqué de presse: Coûts de la main d'œuvre dans l'UE. EUROSTAT. 1er avril. 2016 [Press release. Cost of labor in the UE. EUROSTAT. April, 2016]. French.

25. Starkie HJ, Briggs AH, Chambers MG, Jones P. Predicting EQ-5D values using the SGRQ. Value Health. 2011;14(2):354-360.

26. O'Hagan A, Stevenson M, Madan J. Monte Carlo probabilistic sensitivity analysis for patient level simulation models: efficient estimation of mean and variance using ANOVA. Health Econ. 2007;16(10): 1009-1023.

27. Selya-Hammer C, Gonzalez-Rojas Guix N, Baldwin M, et al. Development of an enhanced health-economic model and cost-effectiveness analysis of tiotropium + olodaterol Respimat ${ }^{\circledR}$ fixed-dose combination for chronic obstructive pulmonary disease patients in Italy. Ther $A d v$ Respir Dis. 2016;10(5):391-401.

28. van Boven JF, Kocks JW, Postma MJ. Cost-effectiveness and budget impact of the fixed-dose dual bronchodilator combination tiotropiumolodaterol for patients with COPD in the Netherlands. Int $J$ Chron Obstruct Pulmon Dis. 2016;11:2191-2201.

29. Boland MR, van Boven JF, Kocks JW, et al. Mapping the clinical chronic obstructive pulmonary disease questionnaire onto generic preference-based EQ-5D values. Value Health. 2015;18(2):299-307.

30. Kruis AL, Ställberg B, Jones RC, et al. Primary care COPD patients compared with large pharmaceutically-sponsored COPD studies: an unlock validation study. PLoS One. 2014;9(3):e90145.

31. Hoogendoorn M, Corro Ramos I, Baldwin M, et al. Cost-effectiveness of the fixed-dose combination tiotropium + olodaterol based on the DYNAGITO trial results [poster abstract]. European Respiratory Journal. 2018;52(Suppl 62):PA3153.

32. Luciani L, Hoogendoorn M, Corro Ramos I, et al. PRS49 - Costeffectiveness of the fixed-dose combination tiotropium + olodaterol based on the DYNAGITO trial results in France [poster abstract]. Value in Health. 2018;21(Suppl 3):S412.
International Journal of COPD

\section{Publish your work in this journal}

The International Journal of COPD is an international, peer-reviewed journal of therapeutics and pharmacology focusing on concise rapid reporting of clinical studies and reviews in COPD. Special focus is given to the pathophysiological processes underlying the disease, intervention programs, patient focused education, and self management protocols.

\section{Dovepress}

This journal is indexed on PubMed Central, MedLine and CAS. The manuscript management system is completely online and includes a very quick and fair peer-review system, which is all easy to use. Visit http://www.dovepress.com/testimonials.php to read real quotes from published authors. 